\title{
Process capability indices for profiles: a systematic literature review
}

Giselle Elias Couto ${ }^{1}$, Federal Center for Technological Education Celso Suckow da Fonseca, Rio de Janeiro, Brazil

Pedro Carlos Oprime², Federal University of São Carlos, São Carlos, São Paulo, Brazil

Gilberto Miller Devós Ganga ${ }^{3}$, Federal University of São Carlos, São Carlos, São Paulo, Brazil

RESUMO

Objetivo - Este artigo tem como objetivo fornecer uma revisão sistemática da literatura sobre índices de capacidade de processo para dados de perfil.

Desenho / metodologia / abordagem - Realizou-se uma Revisão Sistemática da Literatura (RSL). As buscas da RSL foram realizadas nas bases de dados Web of Science, ProQuest e Scopus, delimitando artigos de periódicos acadêmicos com acesso disponível, escritos em inglês e publicados até maio de 2020.

Resultados - Os resultados encontrados indicam que se trata de uma área de pesquisa recente, com publicações apenas na última década. Além disso, a maioria dos índices de capacidade do processo foram desenvolvidos para perfis lineares simples. Estudos futuros devem investigar perfis mais complexos, considerando a autocorrelação e a condição de não normalidade dos dados do perfil.

Originalidade / valor - Este estudo contribui para a comunidade acadêmica uma vez que mapeia a literatura disponível sobre índices de capacidade de processo para dados de perfil, identifica as técnicas e os tipos de perfis mais estudados e indica as lacunas presentes na literatura sobre o tema, possibilitando um direcionamento para estudos futuros.

Palavras-chave - Índices de capacidade de processo; Perfis; Dados funcionais.

\section{ABSTRACT}

Purpose - This paper aims to provide a Systematic Literature Review on process capability indices for profile data.

Design/methodology/approach - A Systematic Literature Review (SLR) was carried out, where the Web of Science, ProQuest and Scopus databases were searched, and articles from accessible academic journals, written in English and published until May 2020, were specified.

Findings - The findings show that this area of research is relatively recent, with publications only found over the last decade. Furthermore, most process capability indices have been developed for simple linear profiles. Future studies may investigate more complex profiles considering the autocorrelation and non-normal condition of profile data.

Originality/value - This study contributes to the academic community in the sense that it maps the available literature on process capability indices for profile data, identifies the techniques and the profile types most studied, and indicates the gaps found in the literature on the subject, providing a direction for future studies.

Keywords - Process capability indices; Profiles; Functional data.

1. R. Gen. Canabarro, 485 - Maracanã, Rio de Janeiro - RJ, CEP: 20271-2041, Brasil. giselle.couto@outlook.com, https://orcid.org/0000-0001-9248-6447; $\quad 2 . \quad$ pedro@dep.ufscar.br, $\quad$ https://orcid.org/0000-0002-6213-2223; 3. ganga@dep.ufscar.br, https://orcid.org/0000-0001-9328-5727.

COUTO, G.E.; OPRIME, P.C.; GANGA, G.M.D. Process capability indices for profiles: a systematic literature review.

GEPROS. Gestão da Produção, Operações e Sistemas, v.16, nº 1, p. 109 - 121, 2021.

DOI: http://dx.doi.org/10.15675/gepros.v16i1.2723 


\section{INTRODUCTION}

The quality concept has been studied, defined, and improved by many researchers over the years. According to Montgomery (2016), quality can be understood as being inversely proportional to variability. This definition highlights the importance of studying the manufacturing processes variability since its reduction results in the desired increase in product quality.

No matter how well designed and controlled a production process is, it will always be subject to variability. Whether because of natural causes of variation, resulting from factors inherent to the process, or because of special causes, which represent sporadic deviations in their behavior. Process capability analysis is a useful technique for statistical process control for quantifying and analyzing this variability in relation to product requirements or specifications.

Traditionally, statistical process control applications consist of process or product performance monitoring using measurements of a single quality characteristic, or a vector of quality characteristics, in a given time or space. However, in some cases, the process or product quality is best characterized and summarized by a functional relationship between one or more response and explanatory variables. This functional relationship is often called a profile (MALEKI; AMIRI; CASTAGLIOLA, 2018). Technological advances have made it possible to collect numerous measurements in process control to reconstruct the profiles and understand its stability over time using statistical methods (COLOSIMO; SEMERARO; PACELLA, 2011).

Process capability indices traditionally used requires some assumptions, such as independence between the observations and that the data meet the normality condition. However, most of the processes represented by profiles produce non-normal and correlated data, and the use of these indices can produce misleading results.

The present paper aims to provide a systematic literature review to answer the following questions: What is being addressed in the literature on process capability indices for profiles? What gaps are in the literature that can provide future research ideas? 


\section{RESEARCH METHOD}

This section describes the steps for preparing the Systematic Literature Review (SLR). The SLR searches were performed in the Web of Science, ProQuest and Scopus databases, delimiting articles from academic journals with available access, written in English and published until May 2020. Table 1 shows the research protocol and Figure 1 shows the review process flowchart.

Table 1 - SLR research protocol

\begin{tabular}{|c|c|}
\hline \multicolumn{2}{|r|}{ Research Protocol } \\
\hline Database & Web of Science; ProQuest; Scopus \\
\hline Publication years & Papers published until May 2020 \\
\hline Document type & Articles and Conference Papers \\
\hline Language & English \\
\hline Strings & $\begin{array}{l}\text { ("profile* monitoring" OR "functional data" OR "profile } \\
\text { analysis" OR "quality profile" OR "linear profile" OR } \\
\text { "nonlinear profile" OR "regression profile" OR "multiple } \\
\text { linear profile" OR "polynomial profile" OR "functional } \\
\text { regression" OR "nonparametric profile" OR "parametric } \\
\text { profile" OR "multivariate profile" OR "geometric profile" } \\
\text { OR "circular profile") AND ("process capability") }\end{array}$ \\
\hline Inclusion criteria & - PCI development for capabality analysis of profile data \\
\hline Exclusion criteria & $\begin{array}{l}\text { - Examples of application of existing PCIs for profiles } \\
\text { - Review literature about profile analysis }\end{array}$ \\
\hline
\end{tabular}

Source: authors. 
Figure 1 - SLR flowchart

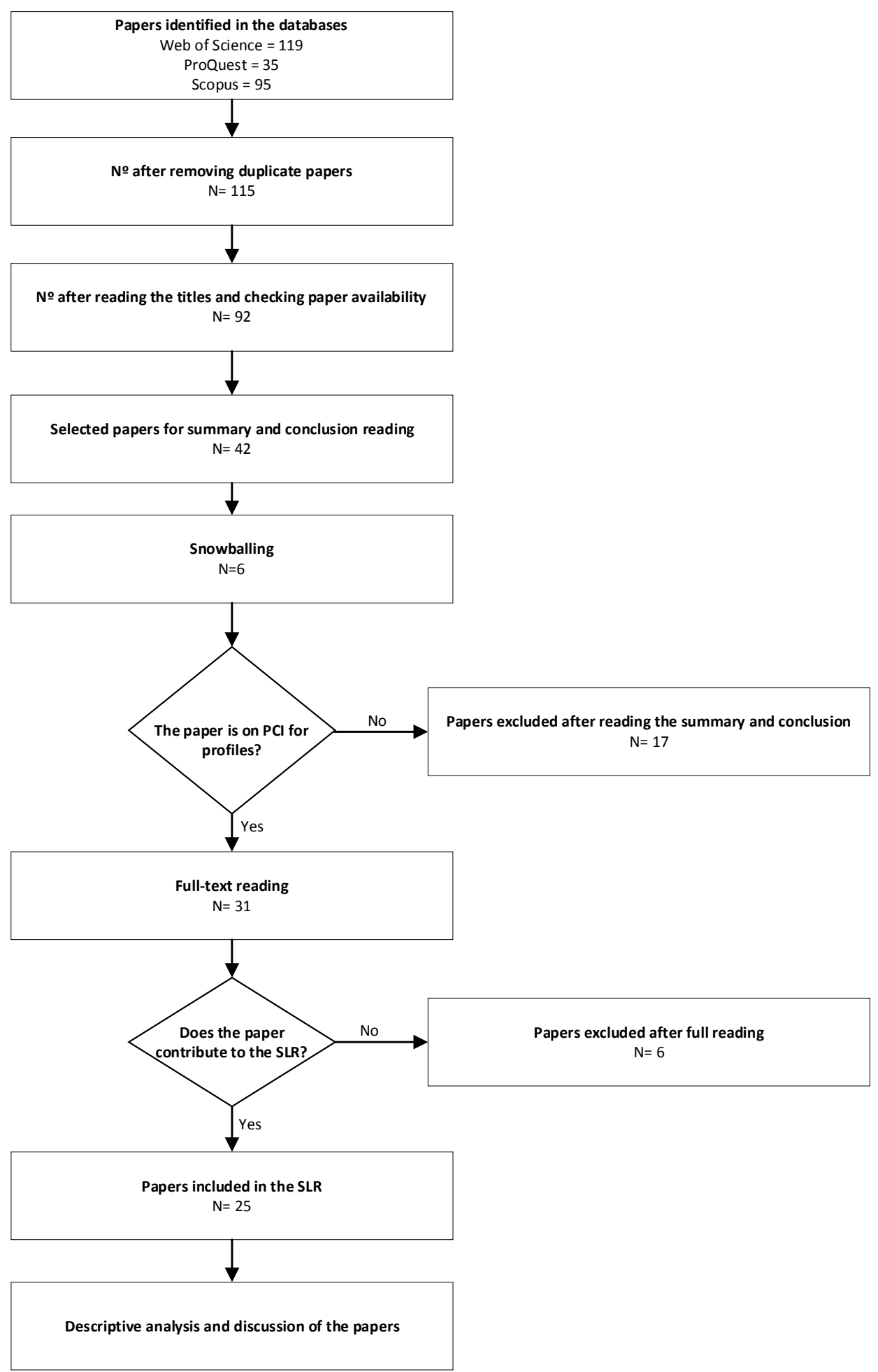

Source: authors. 
As exclusion criteria, duplicate papers within each search, or between different databases, and papers whose full-text access was not available, were removed. Also, to discard the papers that contained the search words, but was not related to the theme, the titles of the remaining papers were read after the application of the first exclusion criterion. The initial number of papers and the number after the exclusion criteria application is in Figure 1.

After the use of the two exclusion criteria, the abstract and conclusion of 42 papers were read. In the snowballing step, references and citations identified in these papers, which were related to the PCI for profiles and that were not contained in the search results, were added to the reading. Papers published after the initial search were also included in this step as an update of the research. After this step, 33 papers were selected for full-text reading. Papers with only applications of the PCI for profiles developed in other studies were eliminated. Finally, 27 papers were considered for the SLR.

\section{RESULTS PRESENTATION AND DISCUSSION}

Regarding the number of published papers, as shown in Figure 2, the maximum and minimum quantities occurred in 2014 and 2017, respectively. It is noteworthy that studies have only been found since 2012, showing that this subject is recent in the literature.

Figure 2 - Number of publications per year

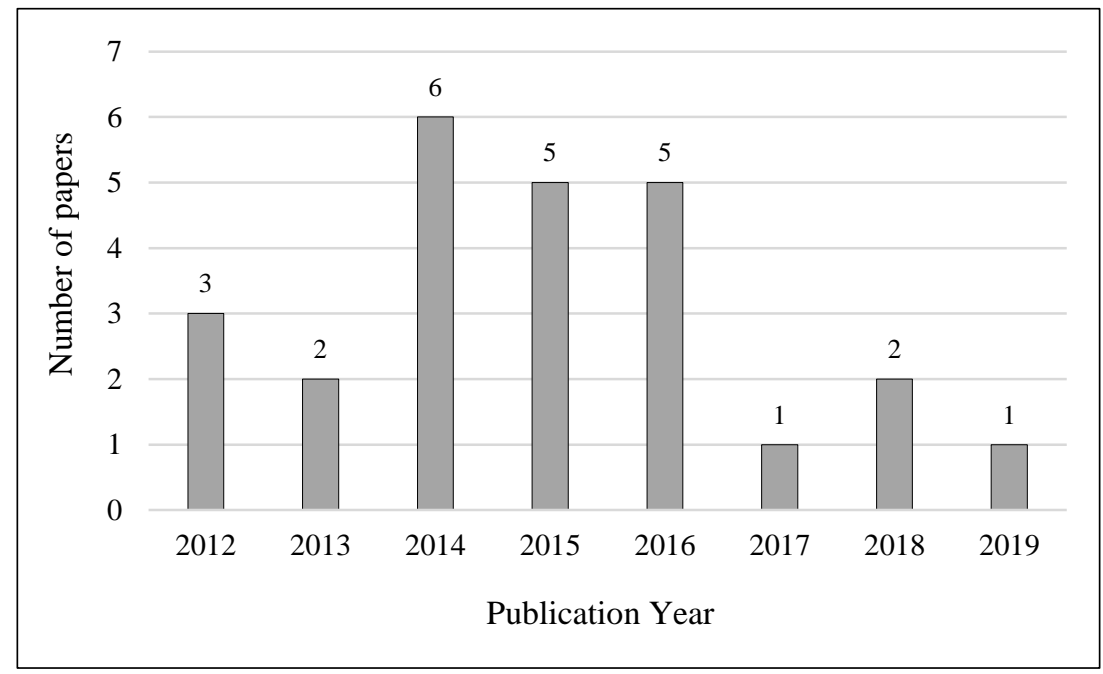

Source: authors. 
As can be seen in Figure 3, there is considerable collaboration between authors, with most authors having published two to three papers on the topic. It highlights the significant contribution of Wang and Amiri with 8 and 5 publications on the subject, respectively.

Figure 3 - Number of participations in publications per author

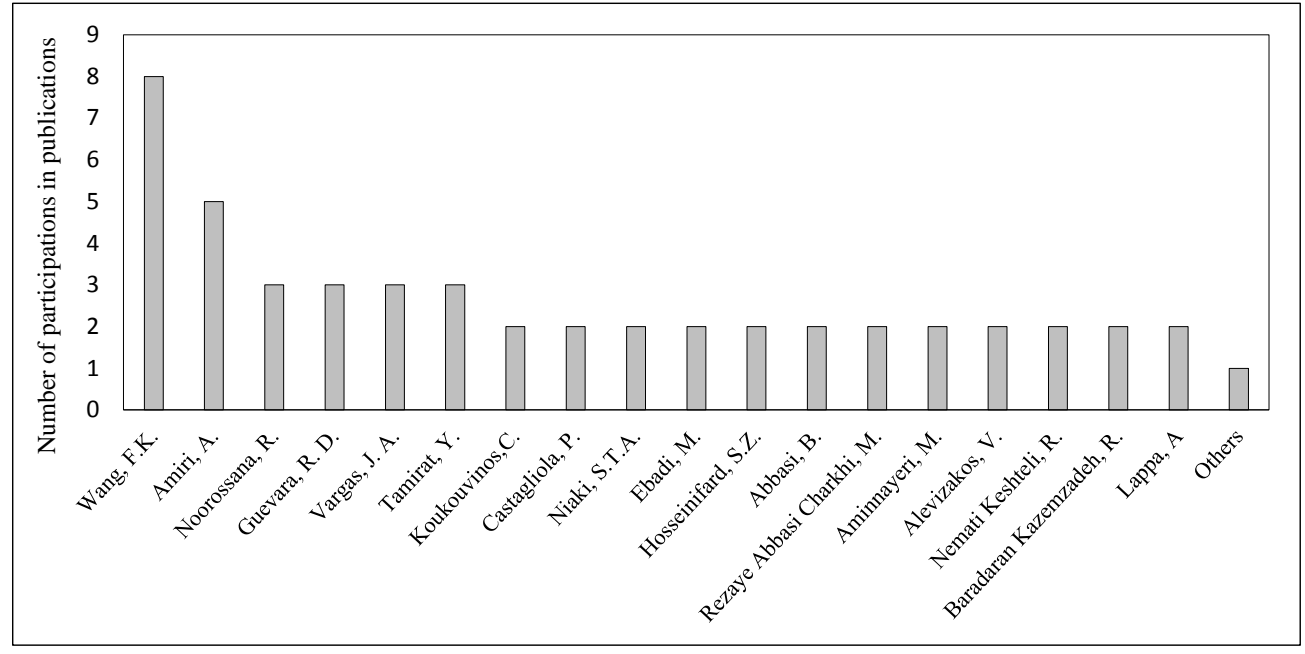

Source: authors.

Regarding the journals of the paper's publication, the Journal Quality and Reliability Engineering International stands out with the highest number of publications. As shown in Table 2, almost $50 \%$ of the papers about the subject were published in this Journal.

Table 2 - Journal and publication frequency

\begin{tabular}{lc}
\hline Journal Title & Frequency \\
\hline Quality and Reliability Engineering International & 11 \\
Quality Engineering & 3 \\
Quality Technology and Quantitative Management & 2 \\
Scientia Iranica & 2 \\
International Journal of Advanced Manufacturing Technology & 1 \\
International Journal of Quality and Reliability Management & 1 \\
Computers and Industrial Engineering & 1 \\
International Journal of Engineering, Transactions B: Applications & 1 \\
Communications in Statistics - Simulation and Computation & 1 \\
Journal of Applied Statistics & 1 \\
Journal of Statistical Computation and Simulation & 1 \\
\hline
\end{tabular}

Source: authors. 
Process capability indices have been developed for different profiles. As shown in Figure 4, most indices were developed for linear profiles, representing $54 \%$ of the studies. Other indices were developed for nonlinear profiles, profiles for generalized linear models (GLM), and circular profiles. For more details on this classification, see Maleki, Amiri, and Castagliola (2018).

Figure 4 - Number of publications per profile type

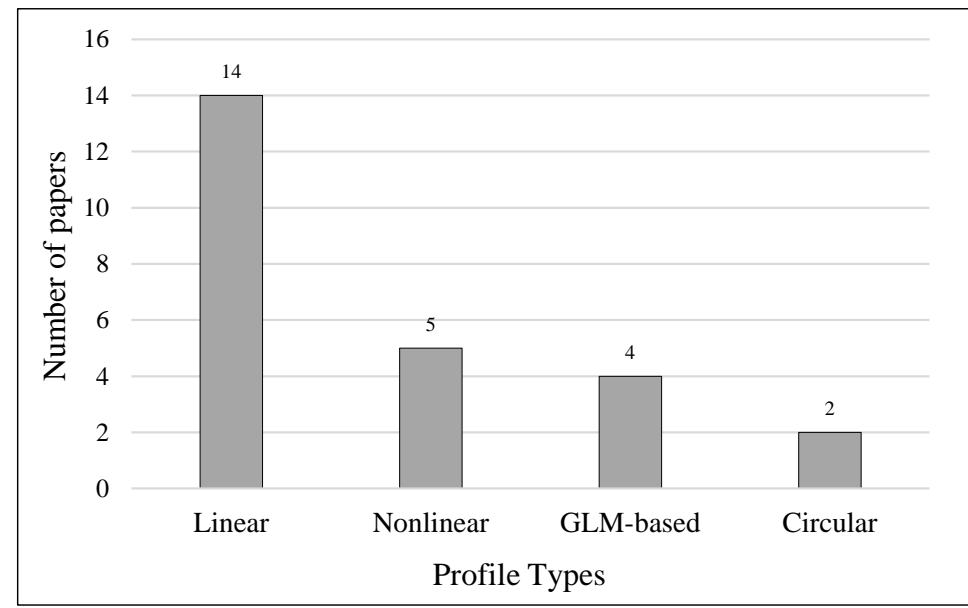

Source: authors.

\subsection{PCI for Linear Profiles}

A linear profile is a simpler type of profile and can be classified as univariate when there is only a single response variable, or multivariate when there is more than one response variable.

Process capability indices for univariate linear profiles were developed by Hosseinifard and Abbasi (2012a), Hosseinifard and Abbasi (2012b), Ebadi and Shahriari (2013), Karimi Ghartemani, Noorossana, and Niaki (2014), Nemati Keshteli et al. (2014), Wang (2014a), Wang (2014b), Wang and Tamirat (2014), Wang and Tamirat (2015), Wang (2016a), Wang and Tamirat (2016) and Chiang, Lio, and Tsai (2017). While process capability indices for multivariate linear profiles were developed by Ebadi and Amiri (2012), Ebadi and Shahriari (2013), Wang (2016a) and Wang and Tamirat (2016).

Ebadi and Amiri (2012) developed three methods to deal with the process capability analysis for multivariate linear profiles. The first is based on the percentage of nonconforming parts produced in each response variable, the second considers a vector of 
multivariate process capability, and the third is based on the principal component analysis. A similar study was developed by Ebadi and Shahriari (2013), comparing a method based on the average percentage of non-conforming parts with a second method based on a multivariate process capability vector of three components. Both works had the methods tested by simulation studies.

Hosseinifard and Abbasi (2012a) compared five methods to assess the process capability for linear profiles with non-normal data: probability plot, Burr percentage, artificial neural network, Box-Cox transformation, and cumulative distribution function. Also, Hosseinifard and Abbasi (2012b) developed process capability indices for linear profiles in which the specification limits are considered as a constant value or a function of the explanatory variable.

Karimi Ghartemani, Noorossana, and Niaki (2014), based on the PCI proposed by Niavarani, Noorossana, and Abbasi (2012), developed an alternative method to estimate the process capability. They assumed a fixed explanatory variable, and specification limits as a linear function of the explanatory variable. Nemati Keshteli et al. (2014) also used functional specification limits to measure the process capability for simple linear profiles.

Wang (2014), Wang (2016a), Wang and Tamirat (2014) and Wang and Tamirat (2015), based on the index proposed by Boyles (1994), proposed a PCI for simple linear profiles, multivariate linear profiles, linear profiles with autocorrelation between themselves, and linear profiles with autocorrelation within each profile, respectively. Subsequently, Wang (2014b) and Wang and Tamirat (2016) also developed process capability indices to measure the performance of processes characterized by univariate and multivariate linear profiles with unilateral specification limits, respectively.

Chiang, Lio, and Tsai (2017) developed two new indices to linear profiles with correlation within the profiles, improving the method proposed by Castagliola and Castellanos (2005) and making its computational use easier. The latest study on PCI for simple linear profile was developed by Abbasi Ganji and Sadeghpour Gildeh (2019) using two fuzzy methods for the circumstances in which lower and upper specification limits are imprecise. 


\subsection{PCI for Nonlinear Profiles}

Considering that in many practical applications a profile cannot be adequately represented by simple linear profiles, some authors have developed process capability indices for nonlinear profiles.

Wang and Guo (2013) and Wang (2016b), based on the index proposed by Boyles (1994), presented a PCI to measure process performance for simple nonlinear profiles and with the presence of measurement errors, respectively. They highlight that the measurement errors have an important effect on the evaluation of the process yield for nonlinear profiles.

As the profile data do not always follow a normal distribution, Guevara and Vargas (2015) proposed two methods to measure the process capability of nonlinear profiles, assuming no distribution for the data. It bases both methods on the depth of the functional data and uses non-normal percentiles to change the classical PCI. Based on this work, Guevara, Vargas, and Castagliola (2016) proposed an alternative method based on the Hausdorff distance. In the same year, Guevara and Vargas (2016) proposed a PCI based on the principal component method for multivariate functional data.

\subsection{PCI for GLM Profiles}

In some applications, when the assumption of normality of the response variable is violated, generalized linear models (GLM) can be used to express functional relationships (MALEKI; AMIRI; CASTAGLIOLA, 2018). Some studies aimed to develop process capability indices for this profile type.

Rezaye Abbasi Charkhi, Aminnayeri, and Amiri $(2015,2016)$ presented a PCI for processes characterized by a logistic regression profile using the percentage of nonconforming items and the process average output. For this same profile type, Alevizakos, Koukouvinos, and Lappa (2018) proposed two methods to estimate the Cp and Spmk indices using the logit, probit, and log-log functions. Both methods include the use of specification limits at each level of the explanatory variable, but the total percentage of non-compliant items is different in each case. In the same year, Alevizakos, Koukouvinos, and Castagliola (2018) proposed another PCI, based on the Spmk index, to measure the process capability when the quality is characterized by a Poisson regression profile. Simulations test the performance of the proposed method showing better performance the greater the number of observations. 


\subsection{PCI for Circular Profiles}

Nemati Keshteli et al. (2014a) proposed functional process capability indices for circular profiles, valid in all ranges of the explanatory variables. They used a reference profile, functional specification limits, and functional natural tolerance limits, to present a functional PCI. An adaptation of these indices, based on the index proposed by Boyles (1994), was presented by Wang (2015). According to the author, when tested through simulation, its index performs better than the one developed by Nemati Keshteli et al. (2014a).

\section{CONCLUSIONS}

This paper presents a systematic literature review on process capability indices for profile data. As shown, this is a recent research area with few publications in the last decade. Because of the improvement in measurement systems technologies and the consequent increase of processes represented by profiles, this is a promising research area. Considering the traditional capability indices restrictions for functional data application, more studies on this topic are necessary. Furthermore, the results show that most of the process capability indices were developed for simple linear profiles and uncorrelated profiles. Thus, future studies should be done to investigate more complex profiles, considering autocorrelation and non-normality data conditions.

\section{References}

ABBASI GANJI, Z.; SADEGHPOUR GILDEH, B. Fuzzy process capability indices for simple linear profile. Journal of Applied Statistics, p. 1-23, 2019.

ALEVIZAKOS, V.; KOUKOUVINOS, C.; CASTAGLIOLA, P. Process capability index for Poisson regression profile based on the Spmk index. Quality Engineering, v.1, p. 1-9, 2018.

ALEVIZAKOS, V.; KOUKOUVINOS, C.; LAPPA, A. Comparative study of the Cp and Spmk indices for logistic regression profile using different link functions. Quality Engineering, v.1, p. 1-10, 2018. 
BOYLES, R. A. Process capability with asymmetric tolerances. Communications in Statistics - Simulation and Computation, v. 23, n. 3, p. 615-635, 1994.

CASTAGLIOLA, P.; CASTELlAnOS, J.V. G. Capability Indices Dedicated to the Two Quality Characteristics Case. Quality Technology \& Quantitative Management, v. 2, n. 2, p. 201-220, 2005.

CHIANG, J. Y.; LIO, Y. L.; TSAI, T. R. M. Control Chart and Process Capability Indices for Simple Linear Profiles with Within-profile Autocorrelation. Quality and Reliability Engineering International, v. 33, n. 5, p. 1083-1094, 2017.

EBADI, M.; AMIRI, A. Evaluation of process capability in multivariate simple linear profiles. Elsevier, v. 19, n. 6, p. 1960-1968, 2012.

EBADI, M.; SHAHRIARI, H. A process capability index for simple linear profile. The International Journal of Advanced Manufacturing Technology, v. 64, n. 5-8, p. 857-865, 2013.

GUEVARA, R. D.; VARGAS, J. A. Evaluation of process capability in multivariate nonlinear profiles. Journal of Statistical Computation and Simulation, v. 86, n. 12, p. 2411-2428, 2016.

GUEVARA, R. D.; VARGAS, J. A.; CASTAGLIOLA, P. Evaluation of process capability in non-linear profiles using Hausdorff distance. Quality Technology \& Quantitative Management, v. 13, n. 1, p. 1-15, 2016.

GUEVARA, R. D.; VARGAS, J. A. Process Capability Analysis for Non-Linear Profiles Using Depth Functions. Quality and Reliability Engineering International, v. 31, n. 3, p. 465-487, 2015.

HOSSEINIFARD, S. Z.; ABBASI, B. Process Capability Analysis in Non-Normal Linear Regression Profiles. Communications in Statistics - Simulation and Computation, v. 41, n. 10, p. 1761-1784, 2012. a.

HOSSEINIFARD, S. Z.; ABBASI, B. Evaluation of process capability indices of linear profiles. International Journal of Quality \& Reliability Management, v. 29, n. 2, p. 162176, 2012. b.

KARIMI GHARTEMANI, M.; NOOROSSANA, R.; NIAKI, S. T. A. A New Approach in Capability Analysis of Processes Monitored by a Simple Linear Regression Profile. Quality and Reliability Engineering International, v. 32, n. 1, p. 209-221, 2014.

KESHTELI, R. N. et al. Developing functional process capability indices for simple linear profile. Scientia Iranica, v. 21, n. 3, p. 1044-1050, 2014. 
MALEKI, MR; AMIRI, A.; CASTAGLIOLA, P. An overview on recent profile monitoring papers (2008-2018) based on conceptual classification scheme. Computers \& Industrial Engineering, v. 126, p. 705-728, 2018.

MONTGOMERY, D. C. Introdução ao Controle Estatístico da Qualidade. 7. ed. [s.1.]: LTC, 2016.

NEMATI KESHTELI, R. et al. Functional Process Capability Indices for Circular Profile. Quality and Reliability Engineering International, v. 30, n. 5, p. 633-644, 2014.

NIAVARANI, M. R.; NOOROSSANA, R.; ABBASI, B. Three New Multivariate Process Capability Indices. Communications in Statistics - Theory and Methods, v. 41, n. 2, p. 341-356, 2012.

REZAYE ABBASI CHARKHI, M.; AMINNAYERI, M.; AMIRI, A. Process Capability Indices for Logistic Regression Profile. Quality and Reliability Engineering International, v. 32, n. 5, p. 1655-1661, 2016.

REZAYE ABBASI CHARKHIA, M.; AMINNAYERI, M.; AMIRI, A. Process Capability Index for Logistic Regression Profile Based on Spmk Index. International Journal of Engineering-Transactions B: Applications, v. 28, n. 8, p. 1186-1190, 2015.

WANG, F. K. A Process Yield for Simple Linear Profiles. Quality Engineering,v. 26, n. 3, p. 311-318, 2014. a.

WANG, F. K. Measuring the Process Yield for Simple Linear Profiles with one-Sided Specification. Quality and Reliability Engineering International, v. 30, n. 8, p. 1145-1151, 2014. b.

WANG, F. K. Measuring the Process Yield for Circular Profiles. Quality and Reliability Engineering International, v. 31, n. 4, p. 579-588, 2015.

WANG, F. K. Process Yield Analysis for Nonlinear Profiles in the Presence of Gauge Measurement Errors. Quality and Reliability Engineering International, v. 32, n. 7, p. 2435-2442, 2016. a.

WANG, F. K.; GUO, Y. C. Measuring Process Yield for Nonlinear Profiles. Quality and Reliability Engineering International, v. 30, n. 8, p. 1333-1339, 2013.

WANG, F. K.; TAMIRAT, Y. Process yield analysis for autocorrelation between linear profiles. Computers \& Industrial Engineering, v. 71, p. 50-56, 2014.

WANG, F. K.; TAMIRAT, Y. Process Yield Analysis for Linear Within-Profile Autocorrelation. Quality and Reliability Engineering International, v. 31, n. 6, p. 10531061, 2015. 
WANG, F. K.; TAMIRAT, Y. Process Yield for Multivariate Linear Profiles with One-sided Specification Limits. Quality and Reliability Engineering International, v. 32, n. 4, p. 1281-1293, 2016.

WANG, F. K. Process yield analysis for multivariate linear profiles. Quality Technology and Quantitative Management, v. 13, n. 2, p. 124-138, 2016. b. 